\title{
"Por nuestros derechos, ahora o nunca!" Construyendo una identidad colectiva umbandista en Argentina
}

\author{
Alejandro Frigerio ${ }^{l}$
}

Las religiones afro-brasileñas, así como otras variantes afro-americanas, se han expandido hacia distintos países. Esta propagación, no planificada ni dirigida, se produce a través de las acciones particulares de individuos brasileros, cubanos, portorriqueños, uruguayos o argentinos (entre otros) que migran por motivos económicos a otros países $-\mathrm{o}$ los visitan por períodos cortos- y allí inician nuevos devotos. Alternativamente, como sucedió en Argentina y Uruguay, la difusión también se debe al accionar de devotos nativos que habiendo conocido la religión en el extranjero la comienzan a practicar en su propio país. Esta propagación sin dirección y algo anárquica posee especificidades locales de acuerdo con el contexto social y la variante religiosa involucrada. Sin embargo, en estas diásporas religiosas secundarias (Frigerio, 2003) manifiestan al menos dos elementos comunes. El primero es la resistencia social que estas religiones generan cuando traspasan ${ }^{1}$ Doutor em Antropologia, professor na Universidad Católica Argentina/Conicet. Endereço:
alejandro_frigerio@il.com.ar 
un determinado umbral de visibilidad o alcanzan un número determinado de practicantes en el nuevo contexto social. El segundo elemento en común es la enorme dificultad que encuentran los líderes religiosos y sus seguidores para organizar respuestas colectivas dirigidas a contrarrestar la estigmatización social que suele acompañar a sus religiones.

Estas dificultades también se presentaron en las ciudades donde se desarrollaron originariamente, pero en estas díasporas religiosas primarias (Frigerio, 2003) finalmente lograron un grado importante de legitimación social. Dicha legitimación, sin embargo, se produjo más por su condición de patrimonio cultural de un grupo étnico que por su naturaleza religiosa (Frigerio, 2002) y sobrevino como consecuencia de otras reivindicaciones negras. Aunque los practicantes en las diásporas primarias han tenido una mayor oportunidad de organizarse colectivamente, tampoco han logrado construir un frente de acción colectiva tan eficaz como el de otros grupos religiosos, como los pentecostales, por ejemplo.

La forma de organización religiosa descentralizada de estas religiones resulta eficiente para su expansión en la medida en que la división celular que da origen a nuevos templos permite adaptaciones rápidas a los nuevos contextos, pero trae graves problemas a la hora de enfrentar las hostilidades sociales. Aunque este tipo de organización permite lograr transformaciones de identidades personales -obteniendo conversiones individuales que posibilitan su expansión- no resulta particularmente apropiado para construir identidades colectivas que permitan un accionar conjunto de los practicantes en beneficio de la comunidad religiosa - obstaculizando, de esta manera, su legitimación.

Utilizando perspectivas desarrolladas en el estudio de movimientos sociales, argumentaré que los líderes religiosos preocupados por la legitimación social de la religión deben desarrollar marcos colectivos de acción que impulsen la construcción de identidades colectivas. Para este fin, deben movilizar recursos económicos y simbólicos al interior y al exterior de su religión, así como aprovechar la cambiante estructura de oportunidades que les presenta el medio social en que se desenvuelven. En este trabajo detallaré los esfuerzos realizados por un grupo de pais y mães de santo argentinos para mejorar la imagen de su religión ante la sociedad y su status legal dentro de ella. Mostraré como desarrollaron sucesivamente distintos marcos y tácticas de acción procurando crear una identidad colectiva que promoviera la movilización de sus fieles. 


\section{Formación de identidades colectivas: aportes desde el estudio de los movimientos sociales}

\section{Grados de centralización de organizaciones religiosas}

Desde comienzos de los 90, distintos autores han llamado la atención hacia los paralelismos existentes entre la literatura dedicada a los movimientos sociales y a los nuevos movimientos religiosos. Una mayor interacción e integración entre estos dos corpus literarios, argumentan, podria llevar a avances conceptuales que beneficiarian a ambos (Hannigan, 1990; 1991; Mauss, 1993). Aunque algunos estudiosos como Hannigan (1990; 1991) han realizado comparaciones partiendo de las teorías de la escuela europea sobre nuevos movimientos sociales, considero mas productivo seguir el camino de Mauss (1993) y aplicar perspectivas desarrolladas dentro de la escuela americana de movimientos sociales, principalmente dentro de la corriente que enfatiza la articulación de marcos interpretativos (Benford y Snow, 2000; Carozzi, 1998). Los estudios de los académicos de la escuela americana, al preocuparse menos por variables macrosociales o procesos históricos prolongados y más por ciertas características específicas de cada movimiento social -cómo estos crean reclamos colectivos, cómo reclutan miembros y movilizan recursos para conseguir sus fines- ayudan a entender mejor las ventajas relativas que algunos de ellos presentan. Por este motivo, sus herramientas conceptuales y teóricas pueden resultar de gran utilidad para el estudio comparativo de grupos religiosos. La aplicación de conceptos y teorías derivadas del estudio de movimientos sociales, que son suficientemente generales como para examinar un espectro diverso de movimientos (étnicos, pacifistas, ecologistas, de derechos civiles o derechos humanos, entre otros), permite la comparación entre dimensiones de análisis de grupos religiosos que habitualmente no resultan realzadas en estudios específicos.

Entre las variables que los estudiosos han considerado como afectando la capacidad de éxito de los movimientos está el grado de centralización de su organización. Snow (1987) señala que algunos estudiosos provenientes de la escuela de movilización de recursos han afirmado que las estructuras burocráticas centralizadas tienden a maximizar las posibilidades de movilización y las probabilidades de éxito. Los defensores de las organizaciones descentralizadas, de base, sostienen -por el contrario- que la institucionalización conspira contra una efectiva movilización ya que ahoga el entusiasmo y canaliza las energías más hacia la construcción de organización que hacia las acciones colectivas. El clásico estudio de Gerlach y Hine (1970) sobre el movimiento pentecostal y el del Black Power en Estados Unidos, sugiere que la descentralización es muy efectiva cuando las partes que com- 
ponen el movimiento están segmentadas y al mismo tiempo interconectadas en forma de red. Un trabajo reciente de Marostica (1997; 2000) sobre los evangélicos en Argentina muestra las dificultades que este movimiento descentralizado debió superar para construir una identidad colectiva y sugiere algunas variables que permitieron que finalmente lo lograran. Entre ellas, una fuerte presión externa, marcos colectivos que interpretaran esta presión como un complot católico y, principalmente, la figura de un evangelista muy popular que a través de sus campañas interdenominacionales logró desarrollar un marco maestro de acción que luego otros tres líderes carismáticos popularizaron para dar impulso a una identidad colectiva. Aunque enfrentada con similares presiones externas, la umbanda argentina no cuenta con instancias interdenominacionales -como la figura del evangelista y sus campañas, periódicos masivos o instituciones paraeclesiásticas- que conecten habitualmente a los distintos grupos. Por el contrario, sus partes componentes sólo forman redes parciales, segmentadas, que no llegan a articularse entre sí. En este trabajo, entonces, partiré del presupuesto de que una organización religiosa descentralizada afecta negativamente a la capacidad de crear identidades colectivas y que es necesario un fuerte trabajo identitario (identity work, según Snow y McAdam, 2000) para remontar esta condición adversa. Esta dificultad aún no ha sido analizada para el caso de las religiones afroamericanas.

\section{Niveles de identidad}

En otro trabajo, siguiendo la pista de perspectivas actuales desarrolladas desde el estudio de movimientos sociales (Snow y McAdam, 2000) y conceptualizaciones que Carozzi (1992) deriva de Goffman para el estudio de las identidades, sugerí que resulta fructífero distinguir entre distintos niveles de análisis de la identidad: personal, social y colectiva (Frigerio, 2002). La importancia de esta distinción radica en que los mecanismos de interacción que se deben poner en movimiento para lograr transformaciones en estos distintos niveles de identidad no son los mismos; los esfuerzos por modificar la identidad personal de quienes se acercan a un grupo religioso no son los mismos ni transcurren en los mismos ámbitos que los realizados para construir una identidad colectiva. Además, para lograr una efectiva movilización colectiva de sus miembros en pro de los objetivos que propone, el grupo debe lograr un cierto grado de correspondencia entre la identidad personal del individuo y la identidad colectiva propuesta por el movimiento. Esta tarea de "correspondencia identitaria" (identity correspondence) supone esfuerzos adicionales y específicos (Snow y McAdam, 2000, p. 47). 
Resulta indispensable, por lo tanto, diferenciar entre la identidad personal de los individuos, sus identidades sociales y la identidad colectiva propuesta por el grupo. Cada uno de éstos términos denota un fenómeno social (y un objeto de estudio) diferente - aunque ciertamente interrelacionados. La identidad personal sería "la conceptualización que la persona realiza de su continuidad como sujeto y de los atributos que la caracterizan y la diferencian en relación a otros seres humanos. Es un producto de la actividad reflexiva. Es el concepto que el individuo tiene de sí mismo como un ser físico, social, espiritual y moral" (Goffman, 1986, p. 56-57 apud Carozzi, 1992). En este caso, la identidad reclamada responde a la pregunta Quién soy yo? Y la respuesta sirve para diferenciar al individuo del resto de sus congéneres. La identidad social sería "la categoria de persona adjudicada a un individuo mediante mecanismos de auto-atribución y atribución por otros, en el curso de la interacción" (Carozzi, 1992, mi énfasis). Estas categorías deben ser sociales, es decir reconocidas por los miembros de una sociedad como agrupando a individuos con alguna/s característica/s similar/es (aunque no organizados para la acción colectiva). Asimismo, que sean atribuídas principalmente -y que sean relevantes- durante las interacciones sociales. En este nivel es donde adquieren mayor relevancia las identidades étnicas, raciales, religiosas. ${ }^{2}$

El tercer nivel de identidad sería el de la identidad colectiva. Este concepto ha sido definido recientemente en una reseña de trabajos sobre el tema como "la conexión cognitiva, moral y emocional de un individuo con una comunidad mayor (...)" (Polletta y Jasper, 2001, p. 285). En otra reseña actual, Snow (2001) coincide en que las discusiones acerca del mismo "sugieren que su esencia radica en un sentimiento compartido de "sentirse unido' (one-ness) o 'sentirse un nosotros' (we-ness), arraigado en atributos o experiencias compartidas real o imaginariamente (...)". Pero a la vez, continúa el autor, "inmerso en este sentimiento colectivo de nosotros hay un sentimiento correspondiente de agencia colectiva. Este sentido, que sería el componente de acción de la identidad colectiva, no sólo sugiere la posibilidad de la acción colectiva en la prosecución de intereses comunes, sino que invita a ejercerla. Por lo tanto, se puede sugerir que la identidad colectiva

\footnotetext{
${ }^{2}$ En las situaciones sociales siempre existe una disputa entre los distintos individuos que participan de ellas por reivindicar para sí o atribuir a los otros una determinada identidad. Por ejemplo, la identidad social reclamada por quienes practican religiones afrobrasileras puede ser "umbandista" (o "africanista"); pero quizás les sea imputada la de "brujo" o "sectario" si prevalece en la situación social la identidad que le es atribuída por otros (miembros de la Iglesia Universal del Reino de Diós, activistas del movimiento anti-sectas etc.).
} 
está constituída por un sentido compartido e interactivo de un nosotros y de agencia colectiva" (Snow, 2001). ${ }^{3}$

La creación de una identidad colectiva definida en estos términos ha sido una de las características típicas asignadas a los movimientos sociales. La misma necesidad muestran, crecientemente, los movimientos religiosos en sociedades industriales avanzadas (Beckford, 2001) - o en economías religiosas desreguladas (Frigerio, 2000) dado que en estas nuevas condiciones deben competir por, y retener a, sus fieles. Deben crear un "nosotros" que propicie a acciones colectivas en beneficio de los fines del grupo. Cuanto más esta acción colectiva se dirija a cambiar algún aspecto de la sociedad, más se parecerá el movimiento religioso a un movimiento social stricto sensu. ${ }^{4}$

Es necesario recalcar que estos tres niveles de identidad no necesariamente convergen o resultan relevantes para todos los integrantes de una agrupación religiosa. Un individuo puede adoptar una identidad social (en contextos religiosos) sin grandes cambios en su identidad personal ni reivindicar la pertenencia a una identidad colectiva. Esta situación es frecuente cuando el individuo se encuentra en las primeras etapas de su relación con un grupo religioso, cuando está reclutado pero aún no se ha convertido totalmente a la cosmovisión del grupo (ver Carozzi y Frigerio, 1997). Alternativamente, un individuo puede adoptar una identidad personal religiosa (ser un converso) pero sin una clara conciencia de pertenecer a un colectivo social, sin llegar a formar una identidad colectiva. Un individuo puede haber adoptado la identidad personal propuesta por el grupo (ser un converso) y puede "pasar" (en términos de Goffman, 1986) de su identidad social en todo contexto que no sea el religioso.

\footnotetext{
${ }^{3}$ Melucci es otro importante teórico de (nuevos) movimientos sociales que enfatiza el carácter construído de la identidad colectiva, así como la necesidad de un componente de agencia colectiva. En su definición de identidad colectiva, afirma que "Es una definición interactiva y compartida, producida por varios individuos y que concierne a las orientaciones de acción y al ámbito de oportunidades y restricciones en que tiene lugar la acción. Es interactiva y compartida porque es una definición que debe concebirse como un proceso, porque se construye y negocia a través de la activación repetida de las relaciones que unen a los individuos (...). [La identidad colectiva] es un proceso a través del cual los actores producen las estructuras cognoscitivas comunes que les permiten valorar el ambiente y calcular los costos y beneficios de la acción" (Melucci, 1995, p. 44).

${ }^{4}$ En una reseña reciente, McAdam y Snow (1997, p. XVIII) han definido a un movimiento social como "una colectividad actuando con algún grado de organización y continuidad fuera de los canales institucionales para el propósito de promover o resistir cambio en la sociedad de la que forma parte". Esta definición refleja bien las utilizadas dentro de la escuela norteamericana del estudio de movimientos sociales.
} 


\section{Marcos de acción colectiva e identidades colectivas}

Entre los elementos necesarios para la creación de una identidad colectiva movilizada para la acción asume particular importancia la elaboración de un marco interpretativo de acción colectiva (collective action frame) (Hunt, Benford y Snow, 1994; Snow, 2001), que postule cuál es la situación de injusticia que se desea remediar, cuál es su origen y qué medidas son necesarias para superarla. ${ }^{5}$ Los marcos también proponen estrategias y tácticas de acción colectiva para llamar la atención hacia el problema y para tratar de imponer sus soluciones (Snow y Benford, 1988; 1992). Por último, señalan quiénes son los destinatarios de la acción, e identifican a los potenciales aliados así como a los principales adversarios (Hunt, Benford y Snow, 1994).

Es muy probable que en un movimiento social -0 religioso- existan opiniones divergentes respecto del diagnóstico del problema y de su solución - que coexistan en su interior distintos marcos de acción colectiva. Podemos entonces hablar no de un solo marco sino de un repertorio de interpretaciones (Mooney y Hunt, 1996) al cual los integrantes de movimientos pueden recurrir para interpretar la realidad. Dentro de este repertorio de marcos interpretativos, en ocasiones se desarrolla un marco determinado (maestro) que logra preeminencia sobre otros y llega a ser compartido por varias organizaciones al interior del movimiento. ${ }^{6}$ Este marco maestro

\footnotetext{
${ }^{5}$ Benford (1997, p. 416) en base a su trabajo anterior con Snow (Snow y Benford, 1992), define los marcos de acción colectiva como "un conjunto emergente de creencias orientadas hacia la acción que inspiran significados y legitiman las actividades y campanas de movimientos sociales". Según Snow y Benford (1992, p.138) los marcos de acción colectiva "subrayan la seriedad e injusticia de ciertas condiciones sociales o redefinen como injusto e inmoral lo que era previamente considerado como desafortunado pero quizás tolerable".

${ }^{6}$ El concepto de "marco maestro" fue introducido por Snow y Benford (1992) para explicar el agrupamiento de similares estrategias retóricas por parte de distintos movimientos sociales durante ciclos de protesta (o de acción colectiva). En su formulación original, se refiere a marcos cuyas funciones interpretativas pueden influenciar a diferentes movimientos sociales. Son genéricos, y de ellos se derivan elementos para marcos más específicos, de movimientos particulares. En este caso, cuando hablo de marco maestro me refiero a "marco maestro de la umbanda/africanismo" ya que no afecta a otros movimientos religiosos, pero sí a distintas agrupaciones dentro del movimiento. Mi uso del término es algo más restringido que el de Snow y Benford (1992) - pero está en la línea de varios autores que también lo han empleado para analizar la evolución de distintos marcos dentro de un mismo movimiento (ver las discusiones al respecto en Mooney y Hunt, 1996; Benford, 1997; Benford y Snow, 2000). Prefiero utilizar maestro a "dominante" o "hegemónico" porque el primer término deja más en claro que son orientaciones generales interpretativas dentro de las cuales pueden subsistir marcos más específicos con algunas diferencias entre ellos. Un análisis más detallado podría encontrar varios marcos específicos culturales sostenidos por distintos líderes argentinos trabajando todos, sin embargo, dentro de un mismo marco maestro cultural. Podría haber -y de hecho las hay- diferencias respecto a si la cultura correcta a mostrar sería la afrobrasilera o la afroameri-
} 
colorea la gama de interpretaciones acerca de la situación que ofrecen los activistas e influye en las estrategias y las tácticas de acción colectiva que se emplean. Su predominio puede ser de duración variable hasta que, por cambios en el contexto social, la acción de antagonistas o por el surgimiento de nuevos activistas con otras interpretaciones, aparezca un marco que dispute su primacía y se transforme en el nuevo marco maestro. Los marcos que pierden su hegemonía, sin embargo, no desaparecen sino que pasan a formar parte del repertorio de interpretaciones, y los activistas -en este caso, líderes religiosos- que proponen nuevos marcos pueden tomar de ellos determinados símbolos, slogans, argumentos o tácticas de acción colectivas (Mooney y Hunt, 1996).

En lo que resta del trabajo, me dedicaré a analizar cómo se construyen los tres niveles de identidad, personal, social y colectiva, para el caso de las religiones afro-brasileras en Argentina. Dado que en otros trabajos he tratado en profundidad el desarrollo de identidades personales y sociales, focalizaré mi análisis en la construcción de identidades colectivas y la sucesión de marcos de acción que los umbandistas/africanistas han desarrollado a tal efecto. Para ello será preciso describir antes el modo de organización descentralizada que posee la religión y la forma en que esta influye en la creación de familias religiosas extensas que crean identidades colectivas parciales. Es esta segmentación la que los líderes a los que nos referiremos luego intentarán superar proponiendo sucesivamente distintos marcos de acción colectiva.

\section{Construcción de identidades personales y sociales en las religiones afrobrasileñas}

\section{La organización religiosa de la umbanda/africanismo}

Desde los pioneros estudios de Herskovits (1954) pasando por el ya clásico trabajo de Lima (1977) se ha caracterizado a la família de santo nucleada en torno de un pai o mãe de santo en un terreiro como la unidad principal de la que se componen las distintas variantes de religiones afrobrasileñas (lo mismo sucede con el ile afro-cubano). El pai o la mãe de santo como interlocutor privilegiado de la voluntad de los orixás, y principal administrador de su axé, se encuentra en la cima de la jerarquía religiosa de cada terreiro y posee un poder de decisión definitivo sobre lo que sucede dentro del mismo. En Argentina es frecuente que el segundo lugar en la jerarquía religiosa lo ocupe el cónyuge del pai o de la mãe - si está iniciado

cana, si sus intérpretes deberian ser devotos o trabajadores culturales, si sólo habría que exhibir danzas y canciones religiosas o también seculares etc. 
en la religión, lo que es casi habitual. Debajo están los hijos de santo, que han sido iniciados por alguno de ellos dentro del camino religioso. Los hijos de santo prontos se encuentran en los niveles superiores de la jerarquía religiosa, por haber realizado la mayor cantidad de iniciaciones rituales. Algunos de ellos tienen varios santos asentados y en algún momento abrirán su propia casa de religión. Otros prontos, que no tienen camino sacerdotal, tendrán asentados su "orixá de cabeza", "de cuerpo" y Bará, el orixá mensajero que siempre acompaña a los demás. Debajo de éstos están los hijos de religión, que tienen una única iniciación, el bori, y por debajo de ellos los médiums de umbanda. Por último, una parte importante de quienes concurren a templos de umbanda/africanismo son los consultantes, los clientes, que principalmente se benefician de los servicios adivinatoros y mágicos de los pais de santo pero habitualmente no son considerados miembros del templo (stricto sensu). El carácter iniciático de la religión, que separa claramente a quienes visten ropa blanca ("médiums", "hijos de religión" e "hijos de santo") de quienes no lo hacen ("el público", "la gente que viene a atenderse", "la freguesía") (Carozzi y Frigerio, 1997) hace que este último segmento difícilmente adopte la identidad social de "umbandista" en sus interacciones y que tampoco participe de las acciones que conducen a la formación de una identidad colectiva. Por ende, la presencia social de los "umbandistas" siempre es bastante menor comparada con la cantidad de gente que, de una manera u otra, se relaciona con los templos de dicha religión.

Grupos de terreiros pueden estar vinculados por su parentesco de santo, si sus líderes fueron iniciados por una misma mãe o pai de santo, conformando de esta manera una familia religiosa extensa. Para el caso del Batuque riograndense, estas relaciones familiares religiosas extensas son especialmente importantes los días de fiestas religiosas en honor a los orixás. Los batuques o fiestas son ocasiones en las cuales estas familias extensas religiosas se visitan y colaboran con su presencia para que la festividad tenga una mayor concurrencia y brillo. Aquí se actualizan -en ocasiones se deterioran- alianzas y se reafirman los lazos de senioridad que entrelazan a los miembros de la comunidad batuquera.

Estas fiestas, sin embargo, siempre son expresiones parciales de esta comunidad. Los líderes e integrantes de diferentes templos que habitualmente concurren a los mismos batuques expresan solamente porciones (de importancia variable) de la comunidad religiosa. Lo hacen porque descienden del mismo pai o mãe; porque viven en la vecindad geográfica (en el mismo barrio o en el mismo partido); porque comparten una nacionalidad en el exilio o simplemente, por sus años de amistad. Los batuques, por lo tanto, expresan tanto las uniones como las divisiones dentro de la comuni- 
dad religiosa. Son la expresión por excelencia de la sociabilidad batuquera, y a la vez el más claro ejemplo de sus límites. Tanto los batuques como las fiestas anuales en homenaje a un guía espiritual de umbanda o a un exú o pomba gira de Kimbanda (éstas últimas siempre muy concurridas) logran crear una sensación de "nosotros" religioso, un primer esbozo de identidad colectiva, pero que sólo expresa a una porción del total de la comunidad de devotos existentes en un país. ${ }^{7}$

Por encima de las familias religiosas extensas, compuestas por padres, hijos y abuelos de santo (y otras derivaciones menos importantes) tenemos las naciones, que reivindican un mismo origen religioso africano y maneras similares de cultuar (mediante cantos, danzas, música) a los orixás (Lima, 1976). La identidad colectiva que se forma a partir de estes rasgos en común, sin embargo, es muy tenue - apenas un elemento que puede superponerse a la familia extensa a la hora de considerar los convidados a los batuques. En ocasiones, especialmente para congresos o en la constitución de federaciones, ha servido como un indicador de qué pueblos o lados (vocablos sinónimos de naciones en Buenos Aires) deben contar con alguna representación.

De una manera u otra, por lo tanto, ya sea por las familias batuqueras extensas o por la -quizás más englobante- noción de nación, las identidades colectivas que la propia organización social de la religión propicia son siempre identidades segmentadas, que habitualmente reflejan, a la vez, una fuerte sospecha hacia el Otro religioso que practica la misma religión pero de manera diferente.

\section{Construyendo identidades personales y sociales}

Si la organización social descentralizada de los templos de umbanda/africanismo dificulta la formación de identidades colectivas más allá de la familia batuquera extensa, resulta, en cambio, bastante eficiente para lograr la transformación de identidades personales. En un trabajo anterior con Carozzi, hemos mostrado cómo se desarolla el proceso de conversión a la umbanda/africanismo en Argentina que lleva gradualmente a la modificación de la identidad personal del individuo en la dirección a la propuesta por el grupo religioso (Carozzi y Frigerio, 1997).

\footnotetext{
${ }^{7}$ Algunas fiestas puedan reunir una gran cantidad de personas. Un famoso pai de santo uruguayo, por ejemplo, cuenta con aproximadamente 50 filiales de su casa. Varios de estos hijos a su vez ya tienen hijos con templos abiertos, con lo que la familia extensa puede nuclear más de 100 templos. Claro que estos son casos excepcionales y las relaciones con todos los parientes de santo no son siempre óptimas - frecuentemente todo lo contrario.
} 
La estrategia habitualmente utilizada por los líderes religiosos en Buenos Aires consiste en introducir a los consultantes $-\mathrm{y}$ potenciales conversos- a situaciones más cercanas a lo conocido primero y más alejadas de su cosmovisión original después. Este proceso gradual toma como punto de partida la práctica del catolicismo popular por quienes se acercan a los templos; éstos, a través del pasaje por la umbanda finalmente llegan a las prácticas y creencias del Batuque. Como resultado de este proceso, el individuo acaba adoptando la identidad personal y (al menos en el templo) la identidad social de hijo de un orixá determinado, que lo llevará a comportarse de determinada manera en el mundo y a interactuar con otros individuos en términos de este conocimiento. En el análisis realizado por Carozzi y Frigerio (1997), se percibe que quienes comienzan a integrarse a terreiros de umbanda primero modifican sus identidades sociales y recién después, aquellos que llegan a convertirse a estas religiones, modifican su identidad personal de acuerdo con los lineamientos propuestos por el grupo.

Este proceso gradual implica el atravesar ciertas etapas necesarias pero no suficientes: muchos individuos permanecen en las primeras o salen del sistema antes de convertirse. En términos de la modificación de las identidades del individuo y de su cosmovisión podemos definir estas etapas como : 1) la adopción en ciertos contextos de la identidad social de consultante y depositario de ayudas espirituales; 2) la adopción de la identidad social de médium y la interpretación de algunas situaciones en términos de la intervención de entidades espirituales; 3) la adopción de la identidad social de hijo de religión y la socialización en la cosmovisión de la variante más ortodoxamente africana practicada en el templo y 4) la adopción de la identidad de hijo de un Orixá en particular como componente central de la identidad personal y el empleo de la cosmovisión del templo en la interpretación de la mayor parte de las situaciones que el individuo atraviesa. ${ }^{8}$

Para enfatizar la no necesaria correspondencia entre los distintos niveles análiticos de la identidad, es necesario resaltar que las modificaciones en las identidades sociales de quienes se acercan y se unen a los templos de umbanda/africanismo pueden no ser aparentes en contextos sociales otros que los religiosos. Las identidades sociales de consultante, médium de umbanda o de hijo de religión pueden ser reivindicadas por los distintos individuos sólo en el contexto del templo, o fuera de éste pero sólo ante pocos familiares y amigos, o en gran parte de las interacciones sociales del individuo, dependiendo de la voluntad que cada uno tenga de "pasar" o de reivindicar su pertenencia religiosa en varias áreas de su vida cotidiana. Ante la estigmatización social de la que son víctimas (que no disminuyó sino que parece

\footnotetext{
${ }^{8}$ Resumo aquí la descripción más detallada realizada por Carozzi y Frigerio (1997).
} 
haber crecido con el pasar de los años) muchos practicantes de estas religiones no reivindican sus identidades sociales religiosas. Esto sin duda también afecta la formación de identidades colectivas puesto que en la medida en que más individuos estén dispuestos a reivindicar su identidad religiosa sólo en contextos religiosos, difícilmente se presten para movilizarse para la acción colectiva que casi siempre debe realizarse en ámbitos extrareligiosos. Por otro lado, la no reivindicación de estas identidades sociales religiosas (o de la de "umbandista", que las englobaría a todas) aumenta la invisibilidad social de la religión y facilita su estigmatización, ya que la imagen pública de la misma queda principalmente en manos de los medios de comunicación (Frigerio, 1991a; Frigerio y Oro, 1998).

\section{Construcción de identidad colectiva en las religiones afrobrasileñas en Argentina}

Hace mucho tiempo que los pais de santo argentinos -o sus pares uruguayos que migraron hace décadas a este país- son conscientes de la estigmatización que sufre su religión (Frigerio, 1991b). Para superarla, sostienen, es necesaria la unión de todos los practicantes para realizar actividades conjuntas que puedan cambiar su mala imagen pública así como presionar para mejorar el status legal de los templos. De acuerdo con la perspectiva de movimientos sociales aquí utilizada, este diagnóstico acerca de cómo su religión es visualizada por la sociedad y cuáles son las actividades necesarias para modificar este estado de cosas puede ser entendido como intentos por crear una identidad colectiva -y especialmente- movilizada para la acción.

Reseñando datos presentados en mayor profundidad en otros trabajos y actualizándolos, postularé que para el caso de la umbanda/africanismo argentinos, en las últimas dos décadas existieron tres marcos maestros de acción colectiva presentados por un grupo relativamente reducido de pais y mães de santo (cerca de una docena) que sucesivamente fueron adquiriendo popularidad entre sus colegas. ${ }^{9}$ Desde 1985 hasta 1989 prevaleció un marco maestro de acción colectiva religioso, desde 1990 hasta el 2000 prevaleció uno cultural, y a partir de esa fecha y con mayor intensidad durante el 2002 se desarrolló un marco maestro de acción colectiva civil. En virtud de la vigencia de cada uno de estos marcos maestros se utilizaron distintas tácticas de acción colectiva que se fueron añadiendo al repertorio de acción

\footnotetext{
${ }^{9}$ En trabajos anteriores he analizado los esfuerzos de acción colectiva de los umbandistas enfatizando su carácter de estrategias acomodaticias - hacia afuera de la comunidad religiosa (Frigerio, 1997; 2002). Aquí deseo subrayar las funciones que cumplen hacia adentro de la misma, como intentos de crear una identidad colectiva.
} 
colectiva (Tilly, 1978) del movimiento. Algunas de estas tácticas pasaron de un marco a otro mientras que otras parecen haber sido abandonadas.

Estos tres marcos comparten de manera general el diagnóstico del problema a enfrentar por la comunidad religiosa y difieren, principalmente, en el elemento pronóstico, o sea, las estrategias de acción que recomiendan y las tácticas que utilizan para implementarlas. ${ }^{10}$ Existen asimismo, algunas diferencias en cuanto a quiénes son considerados, dentro de los distintos marcos, como los principales destinatarios de la acción colectiva y quienes son visualizados como sus aliados y principales adversarios.

El diagnóstico respecto de cuáles son los problemas que enfrentan los umbandistas/africanistas en Buenos Aires se mantiene constante desde el primer intento por crear una identidad y una acción colectiva en la búsqueda por superar la disgregación a la cual una organización descentralizada parece haberlos condenado. Ya en los objetivos de la Confederación Espírita Umbandista -de corta vida- fundada a fines de 1979 se expresa el propósito de "unir todos los centros y terreiros de umbanda sin reparar cual fuera su nación". Se señala, asimismo, el propósito de luchar por "la reafirmacion del derecho constitucional en lo referente a la libertad de cultos". ${ }^{11}$ La construcción de una comunidad religiosa -o de una identidad colectiva, según la terminología aquí utilizada- y la búsqueda de una mayor legitimidad de la religión serán los principales ejes sobre los cuales recaerán los intentos de acción colectiva de los umbandistas. La búsqueda de legitimidad se dirigirá en un primer momento principalmente hacia el ámbito legal, y luego, una vez asegurado éste, hacia el ámbito social, buscando influir en la imagen transmitida por los medios de comunicación.

\section{Formación de una identidad colectiva religiosa (1985-1989)}

Con el retorno de la democracia a la Argentina a principios de 1983, los umbandistas/africanistas comenzaron a practicar su religión más visiblemente; ceremonias que antes se hacían sólo entre conocidos comenzaron a realizarse abiertamente y más templos se identificaron públicamente como tales. Aunque la umbanda no era uno de los nuevos grupos religiosos que en este momento generaron preocupación social, su imagen pública era la de una "secta mágica". La matanza de animales era ya en esta época su carac-

\footnotetext{
${ }^{10}$ Según Benford y Snow (1988) los marcos de acción colectiva cumplirian funciones diagnósticas (identificar un problema y atribuirle una causa), pronósticas (ofrecer soluciones, identificar qué actores serán los blancos de la acción y proponer estrategias y tácticas para la misma) y proveerían un vocabulario de motivos para justificar la acción.

${ }^{11}$ De la ficha de inscripción de esta entidad en el Registro Nacional de Cultos.
} 
terística más controvertida, generando algunas reacciones públicas, especialmente de las sociedades protectoras de animales que reclamaban que estas práctica debían ser prohibidas al encuadrarse dentro de la Ley Sarmiento de protección a los animales (Frigerio, 1991a).

Para mejor salvaguardarse de las críticas sociales y de la aún supérstite -aunque disminuida- represión policial, las inscripciones de templos de umbanda en el Registro Nacional de Cultos no Católicos se multiplicaron durante este período. Probablemente muchos de estos pedidos de inscripción eran de templos nuevos, pero también los había de líderes con años de actividad mas o menos clandestina que pensaban que el nuevo Estado democrático sería un interlocutor más receptivo a sus peticiones que el régimen militar anterior. Aunque no había impedimentos legales para su registro -de hecho, existían inscripciones de templos de umbanda desde 1979las autoridades de la Secretaría de Culto miraban con algo de recelo esta creciente presencia religiosa. El status ambiguo de la religión a nivel oficial queda claro en el editorial de una de las revistas de umbanda editadas en la época:

En una entrevista sostenida con el director de Cultos no Católicos, a los representantes de esta revista no pasó inadvertida la imagen que tiene Umbanda y sus sacerdotes ante ese organismo. Aparentemente, de todos los cultos no católicos éste es el que goza de menos simpatía y aceptación. Razones? Quedaron muy en claro durante la conversación. Falta de representatividad en quienes se presentan invocando su nombre (...) incoherencia en los fundamentos religiosos que alegan ante el Ministerio de Relaciones Exteriores y Culto, e inclusive, falta de presencia decorosa y adecuada para un sacerdote. (...) También es notoria, para los funcionarios, la falta de organización del culto, de una cúpula religiosa representativa e idónea (...). Esta es la imagen que ciertos sacerdotes de Umbanda dan ante el Ministerio. (editorial de Umbanda Argentina, n. 5, 1985)

Ante la sospecha imperante en los medios y en ámbitos oficiales de que la umbanda no sería una verdadera religión, sino una secta mágica cuya principal actividad era el sacrificio de animales, un grupo de pais de santo comenzó a realizar una serie de acciones colectivas con el propósito de nuclear a los umbandistas y demostrarle a la sociedad argentina que esta imagen de la religión era errónea. Esta docena de líderes, casi todos pertenecientes a la primera camada de pais argentinos, establecieron unas relaciones de trabajo -intercaladas con episodios conflictivos entre ellos- por las cuales apoyaban a quienes dentro de ese grupo realizaban eventos públicos. El consenso general que los unía era que la realización de eventos públicos en los cuales explicaran sus creencias y mostraran sus rituales -en un contexto que mostrara las características sociales opuestas a las que se les asignaban- llamaría la atención de los medios que habitualmente los ignoraban o menospreciaban y serviría para aclarar las dudas que existían sobre la religión. 
Los eventos públicos paradigmáticos dentro de este marco de acción colectiva religioso fueron el Primer Congreso Argentino de Umbanda y sus Raíces (25/10/1985), la Festi-Concentración Umbandista y Rituales Africanos (19/6/1986) y el Encuentro de Confraternidad Umbandista Distinción Pai Miguel (16/7/1987). El Primer Congreso resultó particularmente importante no sólo por haber sido la "presentación en sociedad de la religión" -según palabras de su organizadora- sino también porque, al ser la primera cristalización de una acción colectiva, estableció y transmitió distintos elementos diagnósticos y pronósticos del marco de acción colectiva así como tácticas de acción que luego se reproducirían en otros eventos. Entre los elementos diagnósticos, la expresión pública y reiterada (en los objetivos señalados en el afiche del congreso y en su programa) de la necesidad de construcción de un "movimiento religioso umbandista" (sic) local y de unión de esta comunidad religiosa. Entre los pronósticos, la reiterada argumentación, tanto en las ponencias de los pais argentinos, como en las entrevistas a los medios, de que la umbanda poseía todas las características formales de una religión, y por lo tanto no era una secta o curanderismo.

Entre las tácticas se pueden señalar la adopción de modelos derivados del quehacer académico como la organización de congresos con ponencias presentadas por pais de santo en las cuales se detallaban las creencias y la historia de la religión; su realización en lugares céntricos y prestigiosos (hoteles o teatros), la concurrencia a los mismos con ropas formales (trajes, vestidos). Estas tácticas funcionaban hacia el exterior de la comunidad religiosa, como "desidentificadores" (en el sentido de Goffman, 1986), como signos que apuntaban a desmentir la imagen prevaleciente en la sociedad de que los Umbandistas eran socialmente inadecuados (ver Frigerio, 1991b). Pero también funcionaban hacia el interior de la propia comunidad, transmitiendo información, creando una posibilidad de discusión de aspectos doctrinarios e históricos, e instruyendo a otros líderes y devotos, menos preparados que los disertantes, acerca de qué tipo de argumentos utilizar cuando se les preguntara acerca del propósito y origen de la umbanda. Hay que considerar, asimismo, las funciones emotivas de creación de pertenencia y de orgullo comunitario que las reuniones de un millar de devotos bien vestidos concurriendo a un prestigioso local céntrico tienen para habitantes de los suburbios que de otra manera difícilmente llegarían a estos ambientes.

Después del I Congreso se realizaron de manera más privada reuniones de varias decenas de líderes religiosos con la intención de armar un plan de acción colectivo, e idealmente, una "cúpula religiosa" que pudiera oficiar de interlocutor con el Estado, y controlar, de alguna manera, la manera en que la religión era practicada en el país, para evitar abusos de quienes concurrían a templos o desvirtuaciones de las creencias. Este tipo de reuniones, con 
mayor o menor poder de convocatoria, con variaciones en los asistentes a las mismas, se continuaron realizando, generalmente después de cada evento público cuyo éxito pareció dar nuevo impulso a la idea de unificación de la religión.

Un elemento que se incorporó al marco de acción colectivo luego del I Congreso, probablemente debatido en las reuniones más privadas, fue la idea de que el movimiento umbandista local debía desarrollarse con independencia de los mentores religiosos brasileros. Aunque entre los objetivos originales del congreso había estado "consolidar la unión de sacerdotes umbandistas de la República Argentina y de los países limítrofes (Brasil y Uruguay)" y por ello varios de los disertantes en el evento eran importantes jefes de federaciones del Brasil, desaveniencias que surgieron con ellos entre los bastidores del evento llevaron a la organizadora a publicar, con posterioridad, una virtual proclama de independencia del movimiento religioso argentino. En la reseña del evento que realiza en su revista, afirma:

Sobre Umbanda propiamente dicha ninguno de los sacerdotes extranjeros aportó conocimientos ni doctrina. No se escuchó de labios de ellos nada que aquí no se supiera. (...) A raíz de la impresión causada por las disertaciones extranjeras... fue unánime la decisión de "cortar el cordón umbilical" con Brasil a nivel de organizaciones. Quedó claro que se continuará, en el futuro, manteniendo los lazos religiosos con los pai y mãe de santo que cada uno tiene, pero se evitarán las filiaciones independientes (de casas) a instituciones organizativas brasileñas (Confederaciones, Federaciones etc.) (...). Si quedó firme el propósito de ir trabajando en la búsqueda de una organización argentina confiable, reconocida en todo el país y formada por argentinos. (Umbanda Argentina 6, p. 12, 1985, mi énfasis)

La incorporación de esta posición en los marcos de acción colectiva de los umbandistas argentinos se refleja en el hecho de que sólo en dos de los casi 20 eventos públicos subsiguientes hubo disertaciones de un grupo de pais brasileros.

El tercer evento masivo, el Encuentro de Confraternidad Umbandista, realizado en el mismo lujoso hotel céntrico que el I Congreso, inauguró una técnica de acción colectiva que se haría muy popular: la de organizar entregas de diplomas, medallas y estatuillas a quienes se hubieran destacado en la difusión de la religión - principalmente a pais y mães de santo, pero también a algunos periodistas y estudiosos de temas religiosos o de cultura afroamericana. La entrega de premios se transformó en una buena táctica para construir una identidad colectiva en la medida en que reconocía a un grupo -numeroso, por cierto- de individuos que se habían destacado en la difusión de la religión. A la vez, incentivaba a la acción colectiva ya que garantizaba la concurrencia de los líderes religiosos a ser mencionados o premiados y la de sus hijos de santo. Los diplomas, enmarcados y colgados luego en paredes visibles de los templos, mostraban también esa distinción a quienes concurrían a ellos como consultantes. 


\section{Formación de una identidad colectiva cultural (1990-1997)}

Luego de un lustro de realizar eventos públicos que mostraron algunos avances pero también ciertos límites en la capacidad de acción colectiva de los umbandistas, los argumentos de algunos líderes religiosos que enfatizaban la estrategia de resaltar los aspectos culturales de la religión fueron ganando más aceptación y de a poco dieron paso a la formación de un nuevo marco maestro de acción colectiva. En la difusión y popularización de este nuevo marco incidieron también dos eventos de importancia que a comienzos de los 90 sacudieron a la comunidad umbandista/africanista y que llevaron al énfasis ya no de los aspectos religiosos, sino de los culturales, en la acción colectiva.

El primer evento significativo fue la visita del Oni (Rey) de Ife (ciudad santa de los Yoruba) a la Argentina, en enero de 1990. Como parte de sus actividades en el país, este rey concurrió a un templo de religión afrobrasilera en Buenos Aires. El contacto que los templos tomaron con la embajada de Nigeria a raíz de su visita brindó un fuerte impulso al nuevo marco maestro. El entonces embajador, un historiador especializado en la diáspora africana, disertó en dos de los congresos organizados por los umbandistas a comienzos de los 90. Su agregado cultural adquirió un protagonismo aún más importante, ya que participó de casi todos los eventos públicos que la comunidad umbandista/africanista realizó durante la primera mitad de esa década. Este respaldo simbólico de la embajada nigeriana contrastó con la fria distancia que la embajada brasilera siempre mantuvo de los templos y de las actividades a las que sus funcionarios eran invitados.

El segundo factor fue el escándalo mediático que estalló en julio de 1992 y que involucró seriamente a la umbanda/africanismo en la creciente controversia sobre sectas en la sociedad argentina. La (infundada) acusación de un sacerdote católico de que un pai de santo había sacrificado ritualmente a una niña en Buenos Aires desató un pánico moral que deterioró gravemente la imagen de la religión, instalando la sospecha de que el sacrificio de animales -que como vimos ya era mal visto- podía llevar a sacrificios de seres humanos (Frigerio y Oro, 1998). Subsiguientes escándalos mediáticos internacionales (la masacre de Waco en abril de 1993) y locales (las acusaciones de abuso de niños realizadas hacia La Familia/ex-Niños de Dios en septiembre de 1993) prolongaron el pánico moral sobre el accionar de las sectas en Argentina durante casi un año y medio. Involucrada en esta vorágine de acusaciones de lavado de cerebros, abusos sexuales y crímenes, la umbanda se fue transformando, para la opinión pública, en una "secta" 
peligrosa y sus practicantes perdieron la capacidad de manejar su imagen pública (Frigerio y Oro, 1998). ${ }^{12}$

En este contexto de creciente estigmatización, los esfuerzos de acción colectiva de los umbandistas comenzaron a orientarse por un nuevo marco maestro. Este marco, a diferencia del anterior, sugería reivindicar ya no a la religión sino a la cultura como el principal elemento constituyente de una identidad colectiva y a un accionar cultural como la principal estrategia de acción colectiva. Sugería, asimismo, la identificación pública de "la religión" ya no con la umbanda, como antes, sino con el africanismo. Como argumenté con mayores detalles en otros trabajos (Frigerio, 1993; 1997; 2002), si el slogan que mejor resumía el marco maestro anterior era "umbanda es religión", para este el apropiado era "africanismo es cultura".

Como las acusaciones que los medios efectuaban hacia la umbanda de realizar asesinatos rituales hacían imposible quitar de esta palabra la carga negativa que había adquirido, la identificación de la religión con el africanismo permitía deslindarse, en cierta medida, de ella. De acuerdo con el nuevo marco maestro de acción colectiva, la legitimación de la religión ya no vendría por mostrar sus características religiosas que la asemejaban al catolicismo, sino por manifestar que pertenecía a otra tradición cultural y religiosa, la africana, que no por diferente dejaba de ser milenaria y de haber dejado marcas indelebles en la cultura latinoamericana y también en la Argentina. Esta interpretación se veía públicamente apoyada por la asistencia de funcionarios de la embajada de Nigeria a los eventos públicos africanistas - un importante recurso simbólico para una comunidad religiosa fuertemente estigmatizada y uno de los pocos apoyos públicos que lograron con una cierta continuidad.

En septiembre de 1991, la mãe de santo del templo de umbanda/candomblé visitado por el Oni de Ifé el año anterior, organizó el Primer Encuentro de Culturas Afro-Americanas, en el que expusieron 55 académicos extranjeros y locales especializados en cultura e historia afroamericanas. Aunque boicoteado por gran parte de la comunidad religiosa, el evento tuvo una muy buena convocatoria académica y de público. Su cierre musical, realizado en el prestigioso Centro Cultural San Martín, reunió a casi todos los bailarines, músicos y cantantes dedicados a géneros afroamericanos en la ciudad ante un colmado auditorio. Probablemente influenciados por este éxito, los líderes umbandistas que organizaron eventos públicos durante la

\footnotetext{
${ }^{12}$ Una encuesta realizada en 1995 para una Comisión Parlamentaria de la Provincia de Buenos Aires de estudio sobre las sectas demuestra la mala imagen de la Umbanda. En una evaluación guiada sobre qué grupos podían considerarse peligrosos, recibe el segundo número de menciones (luego de los Niños de Dios, quienes en 1993 fueron los protagonistas de otro pánico moral sobre sectas).
} 
primera mitad de los 90 reemplazaron el formato de congreso religioso preponderante durante el período anterior por el de congreso cultural. Así, la mayor parte de los congresos subsiguientes ya no incluyeron solamente como oradores a pais de santo sino que destacaron la presencia de funcionarios, sociólogos, intelectuales o afro-argentinos como oradores. Aunque fueron organizados por pais de santo, y contaron con una asistencia mayormente compuesta por practicantes de la religión, los títulos de los principales eventos públicos muestran la prevalencia del marco maestro cultural como orientador de esta acción colectiva:

- Primer Encuentro de Culturas Afroamericanas (1991)

- Primer Congreso Africanista de Psicología y Antropología de Religiones Afroamerindias (1991)

- Congreso Antropológico Latinoamericano de Religión Africanista (1992)

- Simposio Argentino de Cultura Africana (1992)

- Primer Congreso Internacional de Culturas Afroamericanas (1993)

- Congreso Nacional de Cultura y Religión Africanista (1993)

- Seminario de Religión Yoruba (1994)

- Muestra de Artesania y Folklore Afroamericana (1995)

Bajo este marco maestro, las ceremonias públicas de umbanda realizadas en eventos anteriores que incluían trances de médiums porteños y blancos fueron reemplazadas por representaciones escénicas de danzas de los orixás realizadas por activistas culturales negros de origen brasilero o cubano. También se llevaron a cabo en estos congresos exhibiciones de capoeira, rumba, bailes de carnaval afrobahiano o de candombe afrouruguayo. Los eventos más sofisticados, como el I Encuentro y el I Congreso de Culturas Afro-Americanos y la Muestra de Artesania y Folklore Afroamericana exhibieron, además de las danzas, muestras de pinturas haitianas y/o afrouruguayas, fotos artísticas o reproducciones materiales de altares y vestimentas de orixás. Estas representaciones visuales y performáticas ilustraban la cultura africana de la cual hablaban los intelectuales convidados.

Mostrar la cultura africana era, como argumenté en otros trabajos (Frigerio, 1997; 2002a; 2002b), una estrategia acomodaticia hacia el exterior de la comunidad religiosa, pero también servía, hacia el interior de la misma, para construir una identidad colectiva valorada. Siguiendo las tácticas desarrolladas por el marco maestro de acción anterior, estos congresos también se realizaron en localidades muy céntricas pero con aún mayor prestigio cultural. Las sedes de los mismos fueron: el Aula Magna de la Facultad de Medicina, el Centro Cultural San Martín, el Centro Cultural Recoleta, un conocido teatro de la calle Corrientes, y dos tradicionales hoteles céntricos. 
Devotos de los suburbios (más o menos lejanos) del Gran Buenos Aires quienes difícilmente concurrirían a estos sitios tuvieron acceso a ellos gracias a su "cultura". Asistiendo a estos eventos, los devotos dejaban por un momento de ser practicantes de una religión estigmatizada acusados de brujos, y crecientemente, de asesinos, para ser los portadores de una cultura que los hermanaba con otros grupos étnicos y religiosos de numerosos países de América y Africa y que además reclamaba ser una de las raíces ignoradas de la identidad argentina.

Este sentimiento, que en un principio quizás era ajeno a los devotos de menor educación formal y más alejados geográficamente de la capital, se fue haciendo más tangible con cada evento que se realizaba. Para ello contribuían la presencia del siempre bien trajeado agregado cultural de la embajada de Nigeria; la bandera de este país en el escenario (siempre en vez de, o en lugares más centrales que, la bandera brasilera); la asistencia ocasional de otros representantes de embajadas africanas; los videos que mostraban ceremonias en Africa; las danzas de orixás escenificadas por afroamericanos fervorosamente festejadas por los concurrentes; las exhibiciones de arte afro-americano y africano; los estudiosos que refrendaban que la cultura africana era algo de valor o los afro-argentinos que en cuatro oportunidades expusieron en ellos mostrando las raíces negras en la cultura local. De esta manera, el marco maestro que enfatizaba que su religión también era cultura -y que pertenecía a un tronco africano que unía a la comunidad religiosa local con grupos étnicos y religiosos en numerosos países de América y del Africa- se expandió más allá de los líderes que lo propusieron en un principio. Como señalan varios autores de movimientos sociales, los marcos interpretativos generan acción colectiva pero a la vez se van desarrollando y difundiendo a través de esta misma acción.

Otras dos tácticas de acción colectiva se popularizaron durante este período. La primera fue la intensificación de las entregas de premios a pais de santo que se destacaran en la "dignificación y unificación de las naciones Africanista y Umbandista", como señaló el organizador de uno de estos eventos (Premio Estrella de Plata 1991, 28/12/91). Realizados anualmente durante la primera mitad de la década de 1990 estas entregas de premios resultaron particularmente aptos para crear un "nosotros" colectivo que trascendiera los límites del templo o la comunidad batuquera extensa y para que los pais, mães e hijos de santo se (re)conocieran como miembros de una comunidad religiosa. En el Premio Estrella de Plata de 1991, por ejemplo, 118 pais de santo obtuvieron "nominaciones", y dos obtuvieron el premio Estrella de Plata y el Estrella de Oro. Este tipo de diferenciación permitió, a lo largo de los años, ratificar públicamente una jerarquía religiosa: la veintena o treintena de pais que, por su antigüedad en la religión, la cantidad de 
hijos iniciados o por las actividades públicas que realizaron a favor de la religión, merecían ser premiados y por otro lado, el grueso de los líderes que con menos méritos podían sin embargo resultar "nominados". De todas maneras, casi todos los líderes religiosos que asistieron a estos eventos obtuvieron algún tipo de reconocimiento. Por este motivo asistían acompañados por sus hijos de santo y aseguraban una concurrencia numerosa a los eventos. $^{13}$

La primera mitad de la década del 90 también se caracterizó por otra importante modalidad de acción colectiva: la fundación de federaciones. Esta estrategia se vio incentivada por las fuertes acusaciones que contra la religión se efectuaron en los medios de comunicación pero, sobre todo, por un nuevo proyecto de ley que, de sancionarse, aumentaría las exigencias para las inscripciones en el Registro de Cultos. Según el proyecto que se hizo público en la época, para inscribirse en el Registro un grupo religioso debía cumplir alguna de estas cuatro condiciones: a) tener presencia en tres provincias, b) ser la Iglesia oficial de un Estado con el cual el país tuviera relaciones diplomáticas, c) mostrar una presencia secular en el país o d) tener un número de devotos equivalente al $10 \%$ del total de la población del país o de la provincia en la cual existe (Frigerio y Wynarczyk, en prensa). De sancionarse de esa manera, ningún templo de umbanda podría registrarse individualmente - sólo una o varias federaciones lo suficientemente extendidas por el territorio nacional podrían garantizarse las inscripciones.

La constitución de federaciones siempre formó parte del repertorio de acción colectiva de los umbandistas argentinos - sin duda una táctica legada por sus mentores brasileros que la convirtieron en una herramienta popular en ese país. El primer intento de acción colectiva fue, como vimos, una federación en 1979 y durante el período anterior (1985-1989) se habían fundado tres. Pero a partir de 1990, a medida que la controversia sobre sectas se hizo más virulenta y el fantasma de la nueva ley sugería posibles restricciones a la inscripciones en el Registro de Cultos, se produjo un salto cuantitativo y cualitativo en el uso de esta táctica de acción. En el III Congreso Nacional de Cultura y Religión Africanista, realizado en octubre de 1993, un año después que comenzaran las acusaciones sobre crímenes rituales, y luego de varios meses de pánico moral sobre el accionar de las sectas,

\footnotetext{
${ }^{13}$ Las entregas de premios, a la vez, compartían algunas características con los congresos más "culturales" -como la presencia del agregado cultural de la embajada de Nigeria que repartía los premios, la presentación del himno de ese país al comienzo, la representación escénica de danzas de los orixás o de videos de ceremonias de candomble o africanas. Casi todas las ediciones de los premios Estrellas de Plata se realizaron en el prestigioso y amplio auditorio del Centro Cultural San Martín. De esta manera, aún en los eventos menos "culturales" y más populares se transmitían elementos del marco maestro cultural - de hecho, el organizador de los Premios Estrella de Plata también lo fue de tres congresos "culturales".
} 
diez federaciones de religión afro-umbandista se unieron para formar la Comunidad Argentina Religiosa Afro-Amerindia, "una entidad de carácter confederativo que agrupe a todas las instituciones de segundo grado buscando la unión efectiva y definitiva de todos los practicantes de religiones de origen afro-amerindio en la República Argentina" (según consta en la Declaración de Principios, firmada el 2/10/1993 por los directores de las diez federaciones). ${ }^{14}$

De manera distinta a lo sucedido en Brasil, sin embargo, pocas de estas federaciones lograron tener una existencia legal. La unión buscada y públicamente prometida tampoco se logró esta vez. Luego de disputas internas varias de las federaciones se desprendieron de CARAA. La proliferación de federaciones había terminado reproduciendo la lógica de asociación y de faccionalismo que caracterizaban a los terreiros. Una mãe de santo, dirigente de una de las federaciones que había integrado CARAA y quien fuera una de las principales promotoras de esta institución, describe explícitamente este proceso:

Existen federaciones, confederaciones y congregaciones que se constituyeron con el objetivo de defender y difundir los preceptos de la religión africana (...) [aunque] están lejos aún de cumplir con sus objetivos. Veamos las razones: antes los templos competían uno contra otro, buscando tener más adeptos, más prestigio o más captación de feligreses. Luego, los templos se constituyeron en grupos y fundaron federaciones que nuevamente compitieron entre sí, buscando más adeptos, más prestigio o más captación de socios. La rivalidad se hizo tan grande que hoy asistir a una ceremonia de un templo afiliado a la federación "A" implica que a uno lo expulsen de la federación "B". (revista Creencias 2, agosto de 1995)

Para fines de la década de los 90 las acciones colectivas de los africanistas/umbandistas realizadas dentro del marco maestro de acción colectiva cultural habían rendido algunos frutos: obtuvieron algunos aliados (académicos, activistas culturales afroamericanos, contados diplomáticos), pudieron acceder a prestigiosos centros culturales a los cuales como mera "religión" quizás no hubieran arribado y los principales promotores del marco cultural se habían ganado una cierta confianza de los funcionarios de la

\footnotetext{
${ }^{14}$ La finalidad religiosa de la Comunidad no podía dejar de estar resaltada dado que esta confederación pretendía aglutinar a las federaciones que atendían las relaciones entre los templos y el organismo del Estado que regulaba las relaciones con las religiones no católicas. Ciertos rasgos importantes de la iniciativa, sin embargo, muestran que ésta se encuadra dentro del marco de acción colectiva cultural vigente: la declaración es firmada por todos los presidentes de las federaciones en un congreso "cultural" y los nombres de las federaciones enfatizan la africanidad de la religión. Las cinco federaciones fundadas entre 1979 y 1986 llevaban la palabra "umbandista" en su nombre, y sólo una mencionaba la palabra "afro". Por el contrario, las diez federaciones que conformaron CARAA en 1993 enfatizaban la palabra "africana", "afro" o "africanista" en su nombre y sólo dos mencionaban la palabra "umbandista".
} 
Secretaría de Cultos. ${ }^{15}$ Esta mejora en su imagen, sin embargo, se produjo en círculos reducidos: la legitimación social todavía les era esquiva. Los congresos culturales no habían tenido ninguna repercusión en los medios y aunque la intensidad y la frecuencia de las acusaciones contra la religión habían disminuido - junto con el apaciguamento de la controversia sobre las sectas- existían todavía algunos programas de televisión que se encarnizaban con la umbanda y ciertos homicidios comunes que eran interpretados por la policía como "crímenes rituales".

Al mismo tiempo, no se habían podido trascender las separaciones entre las familias batuqueras extensas - la comunidad continuaba casi tan dividida como antes. La idea de los paladines del marco de acción colectiva cultural de que "la cultura es un paraguas bajo el cual todos hablamos el mismo idioma, nadie se mete en los rituales del otro y podemos presentarnos como una comunidad" no resultó tan evidente para todos los líderes. ${ }^{16}$ Dado que la cultura de la que se hablaba era, en realidad, la africana o la afroamericana de géneros o vertientes religiosas más prestigiosas que el batuque (como el candomblé o la santería), no todos los pais de santo estaban dispuestos a ir más allá de su formación religiosa habitual y leer los libros que el marco cultural requería, etc. Por otro lado, el marco de acción cultural traía implícita una presunción religiosa que muchos líderes no aceptaban: la idea de que era imprescindible profundizar en el conocimiento de la mitología de Ifá - considerada como la base de la cultura y religión afroamericana.

Además de la resistencia de varios líderes a incorporar una serie de conocimientos (culturales y religiosos) que no pertenecían específicamente a la tradición batuquera en la cual se enrolaba la mayor parte de los practicantes existían dificultades prácticas para continuar la acción colectiva dentro

\footnotetext{
${ }^{15}$ La regularidad y continuidad de los congresos africanistas, realizados de a dos o tres por año durante la primera mitad de la década de 1990, mermó bruscamente durante la segunda mitad. Desde 1996 en adelante sólo se realizaron dos eventos masivos: una entrega de premios Estrella de Plata (1997), y un congreso religioso, el I Encuentro Internacional Africanista Batuque Exu (marzo de 1999). Existieron otras iniciativas más específicas que no alcanzaron la centena de participantes. Entre ellas, la presentación de un libro sobre el Batuque argentino (julio de 1996), el dictado de un Ciclo de Conferencias sobre Cultura Yoruba en el prestigioso Centro Cultural Recoleta (mayo de 1997), una cena en honor al hijo del Oni de Ife, quien visitaba el país para iniciar a un babalawo argentino (agosto de 1997). El intento más significativo de construcción de una identidad colectiva durante los últimos años de los 90 fue la aparición de Axé - la única revista africanista/umbandista que apareció en los kioscos de diarios durante 15 meses (junio 1997-agosto 1998). Todos estos emprendimientos muestran el afianzamiento del marco de acción cultural, en la medida en que varios de sus principales defensores aparecían como expositores en los eventos o escribían notas en la revista.

${ }^{16}$ La cita proviene de la intervención de un conocido pai defensor del marco de acción colectiva cultural durante la primera reunión del Foro de Religiones Afro-Amerindias, realizada el $30 / 8 / 98$.
} 
del marco cultural. Esta dependía de la alianza con una serie de actores (personal de la embajada de Nigeria, músicos y bailarines afroamericanos, académicos) cuya heterogeneidad y demandas no era fácil de satisfacer a lo largo del tiempo. Implicaba también la necesidad de alquilar costosos teatros o salas de centros culturales que sólo se podían efectuar garantizando un mínimo de concurrentes al evento. Este difícil equilibro de movilización de dinero, aliados culturales y público resultó muy desgastante para el reducido núcleo de pais de santo organizadores de los eventos. Cuando un cambio de funcionarios en la Secretaría de Culto trajo aparejada una mayor presión para cumplir los requisitos burocráticos necesarios ya no para registrarse, sino para no perder la inscripción (Frigerio y Wynarczyk, en prensa), varios de los principales líderes religiosos comenzaron a plantearse formas alternativas de acción.

\section{Formación de una identidad colectiva civil (1998-2003)}

En los últimos años de la década de 1990 comienza a gestarse otro marco de acción colectiva que parece en camino de convertirse en el nuevo marco maestro, con énfasis en la acción en el terreno político y de los derechos civiles y ya no tanto en el cultural ni en el religioso.

A mediados de 1998 la organizadora del primer evento público umbandista, haciendo una evaluación crítica de los intentos de construir una identidad colectiva, propuso, junto con otros líderes, realizar un nuevo tipo de evento y convocó a los jefes de templo a un Foro de Religiones AfroAmerindias para la creación de un Consejo Religioso Nacional. Esta propuesta mantiene los elementos diagnósticos de los marcos anteriores (la necesidad de unión) pero retoma elementos pronósticos del primer marco maestro (religioso) al intentar nuevamente crear una cúpula religiosa. Innova, sin embargo, al proponer una unión pluralista en vez de la unión homogeneizante que se procuraba en años anteriores. ${ }^{17}$ El Consejo Superior Religioso que se pretendía formar no tendría ya la función de homogeneizar ni fiscalizar los rituales, como en intentos anteriores, sino que sería un organismo meramente "conciliador, consultivo y legislativo".

\footnotetext{
${ }^{17}$ Resulta también novedosa la táctica a través de la cual se convida para conformar la unión: una convocatoria abierta a todos los líderes de templos a través de la revista Axé (n. 13, p. 13, jun. 1998). En la misma se detalla que "la reunión tendrá carácter de asamblea" y que "cada sacerdote tendrá voz y voto". Se especifica que no son necesarias invitaciones especiales y que "nadie queda excluido" (su énfasis). Los intentos anteriores por formar una cúpula religiosa -casi todos realizados durante la segunda mitad de la década de 1980- habían sido mediante reuniones en las cuales se invitaba sólo a un grupo de líderes selectos.
} 
En su informe luego de la primera reunión, la organizadora explicita claramente los motivos de esta nueva posición:

Otro punto de conflicto siempre fue el Culto. Como se hace, y quien lo hace, si tiene más o
menos años, si es prestigioso o no lo es, si sabe o no sabe. Si tiene gente o no tiene. Este
aspecto hay que superarlo. Ya no importa quién lo hace ni cómo lo hace. La realidad nos
dice que entre todos, de una u otra manera, con más o menos tradición, estamos y existi-
mos. La verdad no la tiene nadie, cada uno tiene su propia verdad y en conjunto confor-
mamos una realidad con variantes, con matices diversos de una valiosa riqueza cultural.
(carta enviada a los participantes del Foro, con sus conclusiones resumidas por la organi-
zadora - sus énfasis)

La dinámica de las reuniones intentó expresar este criterio más inclusivo. Se propuso que las sedes de las reuniones del Foro fueran rotativas y que se realizaran además reuniones menores, por zonas, para que sus delegados luego llevaran sus inquietudes a las reuniones del Foro. Se intentaba, de esta manera, lograr

(...) un movimiento participativo, no para ganar relevancia algunos sino para reposicionar nuestras prácticas en el lugar correcto. Un movimiento de todos y para todos (...) Un movimiento contemporáneo, dinámico y masivo, sin incursiones en lo ritualístico privado, sino en lo público social. (periódico del Foro de Religiones Africanas y Amerindias, número 0 , página 3, junio de 1999 , mi énfasis)

Pese a estos criterios más flexibles para la unión, tampoco se logró esta vez el consenso para formar un Consejo unificador. Con todo, las reuniones se sucedieron y se formularon algunos objetivos que muestran el énfasis en la acción civil que este nuevo marco sugiere. Luego de meses de discusiones, con varias deserciones y menos apoyos de lo esperado inicialmente, los objetivos formulados fueron los siguientes: ${ }^{18}$

- poner fin a la intolerancia y a las luchas intestinas que no nos permiten proyectarnos socialmente

- proveer de conocimiento filosófico a los religiosos y erradicar los templos pantallas

- normalizar la legalidad de los templos

- formar una red solidaria entre las casas de religión

- formar un cuerpo legal que defienda nuestros derechos

Las modificaciones en la dimensión pronóstica preconizados por el nuevo marco maestro no sólo enfatizan un nuevo tipo de unión -ahora en la diversidad- y una mayor acción en "lo público social " en defensa de sus "derechos" - como señalan las citas anteriores. También cambian, aunque no se señale de manera tan explícita, los principales destinatarios de las acciones colectivas. Dejando de lado los congresos en teatros y centros culturales dirigidos a impresionar, en un primer momento, a los funciona-

${ }^{18}$ Periódico del Foro de Religiones Africanas y Amerindias, número 0, p. 3, jun. 1999. 
rios del área de Cultos del Poder Ejecutivo y a "la sociedad" de manera general, los africanistas/umbandistas ahora realizan reuniones públicas en templos con políticos a los cuales quieren mostrarles su poder de convocatoria o expresarles su apoyo. Así, antes de las elecciones presidenciales de octubre de 1999, se organizaron dos actos de los cuales participaron dos senadores justicialistas. ${ }^{19}$ En diciembre de 2002, ya en campaña para las elecciones presidenciales de abril de 2003, el candidato a vicepresidente por una de las fórmulas más conocidas asistió a un acto organizado por una remozada versión del Foro, ahora denominado Frente de Religiosos Afroamerindios. Días mas tarde, miembros del Frente se entrevistaron con el candidato a vicepresidente de otra popular fórmula. A ambos les entregaron un petitorio detallando seis áreas en las cuales solicitaban se acabara con la discriminación y la exclusión que aqueja a la comunidad religiosa. En el área de Justicia, criticaban principalmente a los impedimentos burocráticos a las inscripciones en el Registro de Cultos; en la de Trabajo y Asistencia Social requerían que se incluyera a los templos en los planes de ayuda social y que se otorgaran subsidios a los comedores para niños que funcionan en algunas casas religiosas; en la de Educación pedían la participación en programas educativos que ayuden a erradicar la discriminación religiosa; en la de Salud que los pais y mães puedan ejercer sus funciones como ministros religiosos en hospitales y que puedan realizar rituales fúnebres en los cementerios y para el área de los Medios de Comunicación solicitaban que se les otorgara derecho a réplica o que se apercibiera a programas en los cuales eran atacados.

Percibiendo que las acciones colectivas derivadas de los marcos maestros anteriores, religioso y cultural, no habían podido avanzar más allá de la reivindicación retórica de su status como "religión" o como "tradición cultural" afroamericana, los africanistas ahora realizan reclamos puntuales por sus derechos como ciudadanos. La frase con la que finaliza la transcripción de las propuestas del Frente lo muestra muy claramente:

Nuestra comunidad religiosa espera que el próximo gobierno esté conformado por un liderazgo plural, como estrategia para iniciar el camino de la recuperación nacional, respetando los derechos de todos los argentinos sin ninguna distinción. Los derechos humanos, los derechos sociales y los nuevos derechos humanos, son patrimonio de todos y cada uno de los argentinos y no bandera de unos pocos. (mi énfasis) ${ }^{20}$

La consigna "iPor nuestros derechos: Ahora o nunca!" -que figura, unida al nombre del Frente de Religiosos Afroamerindios en el sitio web del

\footnotetext{
${ }^{19}$ En octubre de 1999 Fernando de la Rúa es electo presidente y dos años después, en diciembre de 2001, se ve obligado a renunciar a su cargo. Luego de una sucesión de presidentes interinos, en abril de 2003 se vuelven a realizar elecciones presidenciales.

${ }^{20}$ Periódico del Foro de Religiones Africanas y Amerindias, p. 3, ene. 2003 y web site del Frente de Religiosos Afroamerindios.
} 
mismo- sintetiza elocuentemente el énfasis del nuevo marco de acción colectiva. La acentuada preocupación por sus derechos deviene en gran parte de una nueva amenaza que sienten se cierne sobre su status legal. Como consecuencia del cambio de funcionarios del área de Culto y la intensificación de los controles burocráticos sobre los templos muchas de las inscripciones de templos umbandistas en el Registro fueron canceladas. Las relaciones con el principal funcionario del Registro de Cultos, que habían sido muy buenas durante gran parte de la década de 1990 comenzaron a resentirse durante los últimos años. ${ }^{21}$

El apoyo que los africanistas intentaron mostrar a, y obtener de, los candidatos es una tentativa por conseguir nuevas reglas de juego en las cuales no dependan de la presencia o no de determinados funcionarios para asegurarse un status plenamente legal. La importancia de esta variable queda claramente enunciada en la convocatoria abierta de la renovada versión del Foro, el Frente de Religiosos Afroamerindios, que circuló en folletos y aún se puede leer en su site de internet:

(...) Un Estado que ni siquiera nos brinda el mínimo reconocimiento a la gran mayoría: el registro de la Secretaría de Cultos. La cantidad de trabas burocráticas para acceder al permiso (de Registro de Cultos) ya se hace intolerable. (...) Como se entiende que de los más de 3000 Templos que existen en el Gran Buenos Aires sólo estén inscriptos acaso 400? De ellos trascendió que sólo 30 seguirían registrados. (...) No nos consideramos una secta ni ciudadanos de segunda como para merecer este tipo de trato. Esta situación puede cambiar y depende exclusivamente de nosotros! Si sos jefe de templo te convocamos a participar de un ciclo de conferencias en la que los candidatos presidenciales nos explicarán cuáles son sus proyectos y qué acciones van a tomar cuando sean gobierno con los cultos no-católicos. (...) Nosotros tenemos ahora la oportunidad de hacernos escuchar! Para ello te convocamos simplemente para que te unas como líder religioso a este frente que tiene como objetivo principal hacer visible a nuestra religión, más allá de nuestras prácticas religiosas. No nos interesa cuál sea tu nación o quién sea tu pai o mãe. Nos interesa que, compartiendo con nosotros una misma raíz afroamerindia inspirada en sólidos valores de solidaridad y confraternidad, quieras dar algo más por tu religión. Te esperamos. (los énfasis son del texto)

El nuevo marco, a tono con la realidad argentina de los últimos años, resulta bastante minimalista tanto en las tácticas de acción colectiva como en ciertos elementos pronósticos. La principal táctica de movilización de individuos son las reuniones abiertas en templos, como las propiciadas por el Foro, o reuniones con políticos en los mismos lugares, como las organizadas por el Frente en el 2002 o por otros líderes en 1999. En ambos casos, los costos de organización son mínimos, comparados con los alquileres de

\footnotetext{
${ }^{21}$ Se deterioraron gravemente con la mayoría de los líderes religiosos cuando un grupo de ellos lo acusaron de recomendar gestores amigos para tramitar el registro en Cultos. Esta acusación, realizada públicamente en la primera reunión del Foro, en 1998, llevó luego a una denuncia judicial y al procesamiento del funcionario durante el año 2000. Aunque fue sobreseído, se le inició un sumario administrativo cuyo resultado aún está pendiente.
} 
centros culturales o teatros céntricos que se realizaban durante la década del 90. La mayor parte de los eventos tampoco necesitaron de trabajadores culturales afroamericanos ni de académicos. ${ }^{22}$ Las reuniones del Foro, especialmente, tuvieron como protagonistas a los propios jefes de templo, y al debate abierto entre ellos como principal atractivo. La discusión polifónica enfatizó el carácter plural de la unión procurada en esta etapa.

\section{Conclusiones}

Hemos visto que la unidad principal de la cual se componen las distintas variantes de religiones afro-brasileñas es la família de santo nucleada en torno de un pai o mãe de santo en un terreiro. Grupos de terreiros pueden estar vinculados por su parentesco de santo conformando de esta manera una familia religiosa extensa, compuesta por abuelo, padres e hijos de santo. Por encima de éstas existen las naciones, que reivindican un mismo origen religioso africano y maneras similares de cultuar (mediante cantos, danzas, música) a los orixás. Este tipo de organización social de la religión produce identidades colectivas segmentadas y con no pocas veces fuertes sospechas hacia el Otro de la misma religión, pero de distinta familia o nación.

La organización descentralizada pero a la vez fuertemente jerárquica al interior de los templos crea fuertes lazos de dependencia de los hijos respecto de sus pais que hacen que los líderes de otros templos que no forman parte de la familia extensa religiosa sean mirados con fuerte recelo. Dentro de la familia extensa, las jerarquías son reconocidas y naturalizadas. Fuera de ellas, son continuamente disputadas, ya que la posibilidad de que otros líderes sean más importantes o tengan mayor jerarquía que el propio pai o abuelo de santo repercute negativamente hacia adentro de la propia familia. Esto hace que para los intentos de acción colectiva -al igual que para los batuques- un organizador pueda, en primera instancia, sólo contar con el apoyo de su propia comunidad batuquera. Lograr una asistencia mayor requiere de un penoso trabajo de invitaciones personales, persuasión y lisonjeo a los posibles participantes. Por este motivo, el organizador más

\footnotetext{
${ }^{22}$ Algunas de las características de las reuniones públicas muestran, todavía, la presencia de elementos del marco cultural anterior: por ejemplo, en una de las reuniones con políticos realizada en 1999 -en el templo de la mãe que más defendió dicho marco- se realizaron presentaciones de capoeira y de danza de los orixás antes de los discursos más políticos. En la primera reunión del Foro en 1998 uno de los oradores fue el embajador de la república de Nigeria, quien prometió su apoyo a las inciativas que demostrasen la unión de los religiosos locales. Aunque no prevalecen durante este período, su presencia muestra cómo elementos de marcos maestros anteriores pasan a formar parte del repertorio de interpretaciones y de acciones al cual los umbandistas pueden recurrir (Mooney y Hunt, 1996).
} 
exitoso de eventos públicos era uno de los pocos que estaba dispuesto a recorrer uno a uno los distintos templos, aunque no pertenecieran a su familia batuquera extensa ni estuvieran dentro de su área geográfica de sociabilidad.

Los umbandistas, por lo tanto, pueden ser conceptualizados como un movimiento de organización descentralizada cuyas partes componentes (los terreiros) se relacionan en forma de redes segmentadas y habitualmente antagónicas. Este tipo de organización habitual da por resultado la formación de identidades colectivas siempre fragmentadas, distintos "nosotros" que difícilmente puedan fundirse en uno mayor englobante.

Aún cuando obtuvieron un éxito apreciable en la transformación de identidades personales, no lograron traducir esas transformaciones identitarias personales en identidades sociales que pudieran aumentar la visibilidad cotidiana de la religión. En la vida cotidiana argentina, "umbandista" continua siendo una categoría acusatoria y pocas veces una identidad social reivindicada - salvo por los líderes de templos para quienes se transforma en su identidad maestra a la cual otras identidades se encuentran subordinadas. Gran parte de los devotos "pasan" de su identidad social en la vida cotidiana, especialmente en áreas duras de prejuicio, como el trabajo o la escuela. De esta manera los "umbandistas" sólo aparecen mayormente en las noticias policiales o en escandalosos programas de televisión.

Si no lograron que sus devotos articularan sus identidades personales con las sociales, tampoco consiguieron construir una colectiva que les permitiera encarar intentos sostenidos de acción colectiva. En sus intentos de construcción de una identidad colectiva, los africanistas/umbandistas desarrollaron, en las últimas dos décadas, tres marcos maestros que guiaron su accionar. Estos marcos coincidieron a grandes líneas en sus elementos diagnósticos: el problema que aquejaba a la religión era la falta de unión de sus practicantes y la estigmatización social de la que era objeto. Variaban, principalmente, en sus elementos pronósticos - cuáles eran las acciones que debían ser implementadas para remediar la situación y quiénes serían los principales destinatarios de las acciones colectivas. Asimismo, los activistas que proponían los marcos también implementaron o sugirieron distintas tácticas de acción que, junto con los elementos pronósticos se fueron agregando al repertorio de interpretaciones y de acción colectiva al que podrían recurrir los líderes religiosos. Estos marcos de acción colectiva se fueron desarrollando en las interacciones entre distintos líderes, en la propia acción colectiva y de acuerdo con las modificaciones que se iban produciendo en la estructura de oportunidades que les brindaba el cambiante contexto social argentino. 
Las acciones colectivas desarrolladas durante la vigencia del primer marco maestro enfatizaron una identidad colectiva religiosa y la estrategia principal que guió la acción fue mostrar los rituales y explicar cómo la umbanda se ajustaba al modelo social de lo que sería una "religión". Se intentó, a la vez, conformar una cúpula de líderes reconocidos que determinara la manera "correcta" de practicar la religión. Al comenzar la década de 1990, el fracaso por conformar un consejo supremo de sacerdotes, el incremento de las acusaciones contra la umbanda y el apoyo inesperado de la embajada de Nigeria hicieron que se popularizara el marco de acción colectiva cultural que algunos líderes venían desarrollando desde unos años atrás. Varios pais y mães pensaron que el énfasis en la cultura podría ser un paraguas bajo el cual poner sus diferencias en lo ritual y mostrarse hacia fuera como una comunidad unida y que las acusaciones de secta criminal serían refutadas mostrando la pertenencia a un tronco cultural y étnico que influyó en la danza, la música, el arte de casi todos los países americanos. Aunque este marco ayudó a capear el temporal de las acusaciones más graves y permitió que los africanistas/umbandistas lograran algunos apoyos en sectores académicos, artísticos y diplomáticos, luego de unos años mostró sus límitaciones. Dos de las mães de santo que lo propusieron con mayor énfasis fallecieron -una de ellas responsable por los más resonantes eventos culturales realizados- y la cada vez más deteriorada situación económica del país hizo más difícil el alquiler de teatros o de auditorios de centros culturales para realizar los eventos.

El deterioro social y el inesperado desgaste de su relación con funcionarios de la Secretaría de Cultos -un área en la cual los africanistas/ umbandistas habían logrado importantes avances en su legitimación mediante su acción colectiva- llevó al desarrollo de un tercer marco maestro de acción colectiva con énfasis en sus derechos civiles. Fracasados los intentos por construir una identidad colectiva construida en base a la religión y luego apelando a la cultura, algunos líderes religiosos propusieron entonces construir una basada simplemente en la defensa de sus derechos ciudadanos. Aprovechando las elecciones presidenciales -que se repitieron a los dos años- y tomando como ejemplo explícito al lobby realizado desde tiempo antes por los evangélicos con los políticos, realizaron algunas reuniones abiertas con candidatos a los cuales les prometieron apoyo. Su modalidad de acción colectiva, influenciada por los disminuidos recursos económicos, se restringió mayormente a reuniones abiertas en distintos templos en los cuales los concurrentes debatían problemas y líneas de acción. Para evitar mayores divisiones, las discusiones eludieron temas religiosos y enfatizaron la búsqueda de soluciones a los problemas concretos de estigmatizacíon que aún los afectaban. 
Es necesario recalcar que estos marcos de acción colectiva fueron producto de la actividad de una minoría de líderes religiosos. Esta veintena de pais y mães de santo fueron quienes organizaron los eventos públicos; presentaron ponencias en sus congresos o en los organizados por otros; editaron revistas o escribieron en las de otros; dictaron cursos, etc. Qué tanto sus premisas fueron compartidas por otros miembros de la comunidad religiosa dependió de la medida en que cada uno hubiera participado de estas acciones colectivas -a cuántos eventos públicos asistió, qué revistas leyó o qué tan atento estuvo a las apariciones en los medios de estos líderes. La relevancia y la efectividad de estos marcos, sin embargo, se desprende de al menos dos consideraciones. La primera, la coherencia que demostraron los eventos públicos realizados dentro de la vigencia de cada marco maestro con los presupuestos de éstos. La consonancia que muestran los actos realizados en los períodos de vigencia de los marcos que hemos descripto permite concebirlos como ciclos de acción colectiva - parafraseando la conocida expresión de Tarrow (1983) de ciclos de protesta. ${ }^{23}$ La segunda muestra de la relevancia de estos marcos está dado por el hecho de que los discursos que propician son una parte fundamental del repertorio de interpretaciones al que recurren, con mayor o menor frecuencia, los líderes religiosos. Aún aquellos pais que no están interesados en la formación de una identidad colectiva -que están más preocupados por la mera práctica ritual en su templo que por construir un movimiento social umbandista- deben, en las ocasiones en las que se pronuncian sobre la relación entre su religión y la sociedad, recurrir a estos discursos elaborados por la minoría de pais de santo para los cuales esta relación sí es central.

Aunque no he abordado este aspecto aquí, hay que considerar el poder multiplicador que tiene cada persona que asistió a un evento público umbandista respecto de la difusión de los marcos interpretativos que lo generaron. Dada la ubicuidad y relevancia del chismorreo en la vida diaria de los templos - una de las características resaltadas pero poco estudiada de las religiones afroamericanas en general- lo sucedido en eventos públicos, en fiestas de batuque o en sesiones de umbanda, así como las opiniones vertidas por colegas o por detractores en programas de televisión sobre la religión, ocupa un lugar absolutamente central en la vida cotidiana de los templos. De esta manera, aún quienes nunca asistieron a eventos pueden enterarse de lo que aconteció o lo que se dijo en ellos a través de colegas o amigos que sí lo hicieron. Aunque frecuentemente estos chismes tomen el ca-

\footnotetext{
${ }^{23}$ Tarrow denomina ciclos de protesta a "secuencias de creciente acción colectiva cuya frecuencia e intensidad son mayor de la normal, que se difunden a través de varios sectores y regiones de la sociedad y que involucran nuevas técnicas de protesta y nuevas formas de organización..." (en Snow y Benford, 1992, p.141)
} 
rácter de críticas, igual hacen circular las distintas interpretaciones y muchas de las posiciones inicialmente reprobadas son más tarde adoptadas por sus propios críticos - como sucedió con los elementos del marco cultural.

A lo largo del trabajo he analizado las distintas maneras en que los umbandistas han intentado construir una identidad colectiva. Primero, en base a su religión, luego identificándose principalmente con su cultura, y, fracasados ambos intentos, basándose simplemente en la defensa de sus derechos ciudadanos. Los africanistas/umbandistas argentinos parecen estar encontrando que, más que su religión y su cultura, lo que parece unirlos a todos es la discriminación de la cual siguen siendo objeto.

\section{Referências}

BECKFORD, James. Social movements as free-floating religious phenomena. In: Richard FENN (org.). The Blackwell Companion to the Sociology of Religion. Oxford: Blackwell, 2001, p. 229-248.

BENFORD, Robert. An insider's critique of the social movement framing perspective. Sociological Inquiry, v. 67, nº 4, p. 409-430, 1997.

BENFORD, Robert y David SNOW. Framing processes and social movements: an overview and assessment. Annual Review of Sociology, n 26, p. 611-639, 2000.

CAROZZI, María Julia. El concepto de marco interpretativo en el estudio de movimientos religiosos. Sociedad y Religión, Buenos Aires, nº 16-17, p. 33-52, 1998.

La Conversión a la Umbanda en el Gran Buenos Aires. Informe final no publicado. Buenos Aires: Conicet, 1992.

CAROZZI, María Julia y Alejandro FRIGERIO. Batuquero no se nace: convirtiéndose a las religiones afrobrasileñas en Buenos Aires. Religião e Sociedade, Rio de Janeiro, v. 18, $\mathrm{n}^{\circ} 1$, p. 71-94, 1997.

FRIGERIO, Alejandro. Re-Africanization in secondary religious diasporas: Constructing a world religion. Civilizations, Bruselas, 2003, en prensa.

Outside the nation, outside the diaspora: Accommodating race and religion in Argentina. Sociology of Religion, v. 63, nº 3, p. 291-315, 2002.

30. Teorias econômicas aplicadas ao estudo da religião: em direção a um novo paradigma? Revista Brasileira de Informação Bibliográfica em Ciências Sociais (BIB), Rio de Janeiro, no 50, p. 125-144, 2000.

. Estabelecendo pontes: articulação de significados e acomodação social em movimentos religiosos no Cone Sul. In: Ari ORO y Carlos STEIL (Orgs.). Religião e Globalização. Petrópolis: Vozes, 1997. p. 153-178.

-_- De la Umbanda al Africanismo. In: Claudia FONSECA (Org.). Fronteiras da cultura. Porto Alegre: Edufrgs, 1993, p. 92-121.

Nuevos movimientos religiosos y medios de comunicación: la imagen de la Umbanda en Argentina. Sociedad y Religión, Buenos Aires, nº 8, p. 69-84, 1991 a. 
"La Umbanda no es una religión de ignorantes y mediocres": la estigmatización de las religiones afro-brasileñas en Buenos Aires. Revista de Antropología, Buenos Aires, $\mathrm{n}^{\mathrm{o}}$ 10, $\mathrm{p}$. 22-33, $1991 \mathrm{~b}$.

FRIGERIO, Alejandro y Ari ORO. "Sectas satánicas" en el Mercosur: un estudio de la construcción de la desviación religiosa en los medios de comunicación de Argentina y Brasil. Horizontes Antropológicos, no 8, p. 114-150, 1998.

FRIGERIO, Alejandro e Hilario WYNARCZYK. Cult controversies and government control of new religious movements in Argentina (1985-2001). In: James RICHARDSON (Org.). Regulating religion: case studies from around the globe. Estados Unidos: Kluwer Publishing, (en prensa).

GERLACH, Luther y Virginia HINE. People, power, change: movements of social transformation. Indianapolis: Bobbs-Merrill, 1970.

GOFFMAN, Erving. Stigma: notes on the management of spoiled identity. New York: Simon and Schuster, 1986.

HANNIGAN, John. Social movement theory and the sociology of religion: toward a new synthesis. Sociological Analysis, v. 52, nº 4, p. 311-331, 1991.

Apples and oranges or varieties of the same fruit? The new religious movements and the new social movements compared. Review of Religious Research, v. 31, n 3, p. 246-258, 1990.

HERSKOVITS, Melville. Estrutura social do candomblé afro-brasileiro. Boletim do Instituto Joaquim Nabuco, Recife, n 3, p. 13-32, 1954.

HUNT, Scott, Robert BENFORD y David SNOW. Identity fields: framing processes and the social construction of movement identities In: Enrique LARAÑA, Hank JOHNSTON y Joseph GUSFIELD (Orgs.). New social movements: from ideology to identity. Philadelphia: Temple University Press, 1994. p. 185-208.

LIMA, Vivaldo da Costa. A família de santo nos candomblés jeje-nagòs da Bahia. Salvador, 208 p. Tesis (maestría). Pós-Graduação em Ciências Humanas da Universidade Federal da Bahia, 1977. 1976.

O conceito de nação nos candomblés da Bahia. Afro-Asia, Salvador, ${ }^{\circ}$ 12, p. 63-90,

MAROSTICA, Matt. La nueva política evangélica: el movimiento evangélico y el complot católico en la Argentina. Ciencias Sociales y Religión /Ciências Sociais e Religião, Porto Alegre, ${ }^{\circ}$ 2, p. 11-30, 2000.

Pentecostals and politics: the creation of the Evangelical Christian movement in Argentina 1985-1995. Berkeley, 270 p. Tesis (doctorado). Political Sciences Department. University of California, Berkeley, 1997.

MAUSS, Armand. Research in social movements and in new religious movements: the prospects for convergence. Religion and the Social Order, n 3A, p. 127-151, 1993.

McADAM, Doug y David SNOW. Social movements: conceptual and theoretical issues. In: Douglas McADAM y David SNOW (Orgs.). Social movements: readings on their emergence, mobilization and dynamics. Los Angeles: Roxbury Publishing, 1997. p. XVIIIXXVI.

MELUCCI, Alberto. The process of collective identity. In: Hank JOHNSTON y Bert KLANDERMANS (Orgs.). Social movements and culture. London: University College London Press, 1995. p. 41-63. 
MOONEY, Patrick y Scott HUNT. A repertoire of interpretations: master frames and ideological continuity in US agrarian mobilization. Sociological Quarterly, v 37, $\mathrm{n}^{\circ} 1, \mathrm{p}$. 177-197, 1996.

POLLETA, Francesca y James JASPER. Collective identity and social movements. Annual Review of Sociology, $\mathrm{n}^{\circ}$ 27, p. 283-305, 2001.

SNOW, David. Organization, ideology and mobilization: the case of Nichiren Shoshu of America. In: David BROMLEY y Phillip HAMMOND (Orgs.). The future of new religious movements. Macon, GA.: Mercer University Press, 1987. p. 153-174.

Collective identity and expressive forms. In: Neil J. SMELSER y Paul B. BALTES (Orgs.). International Encyclopedia of the Social and Behavioral Sciences. Londres: Elsevier Science, 2001.

SNOW, David y Robert BENFORD. Ideology, frame resonance and participant mobilization. International Social Movement Research, $\mathrm{n}^{\circ}$ 1, p. 197-217, 1988.

Master frames and cycles of protest. In: A. MORRIS y C. McClurg MUELLER (Orgs.). Frontiers in social movement theory. New Haven: Yale University Press, 1992. p. 133-155.

SNOW, David et al. Frame alignment processes, micromobilization and movement participation. American Sociological Review, n 51, p, 464-481, 1986.

SNOW, David y Doug McADAM. Identity work processes in the context of social movements: Clarifying the identity/movement nexus. In: Sheldon STRYKER, Timothy OWENS y Robert WHITE (Orgs.). Self, identity and social movements. Minneapolis: University of Minnesota Press, 2000. p. 41-67.

TARROW, Sidney (1983). Struggling to reform: social movements and policy change during cycles of protest. Ithaca, NY: Western Societies Occasional paper 15, Cornell University, 1983.

TILLY, Charles. From mobilization to revolution. Reading, Mass.: Addison-Wesley, 1978. 